\title{
VI. On the radioactivity of the rocks of the Kolar Gold-Fields
}

\section{Herbert Edmeston Watson D.Sc. \& Gostabehari Pal M.Sc.}

To cite this article: Herbert Edmeston Watson D.Sc. \& Gostabehari Pal M.Sc. (1914) VI. On the radioactivity of the rocks of the Kolar Gold-Fields, Philosophical Magazine Series 6, 28:163, 44-51

To link to this article: http://dx.doi.org/10.1080/14786440708635181

册 Published online: 08 Apr 2009.

Submit your article to this journal $\lceil\pi$

Џ Article views: 1

Q View related articles $₫$ 
(ii.) Interrupter $\mathrm{AC}$; Galvanometer $\mathrm{BD}$.

$\mathrm{C}=0 \cdot 2$ microfarad; $\mathrm{R}=100$ ohms.

Balance undisturbed.

$\mathrm{C}=0 . \pm$ microfarad; $\mathrm{R}=100$ ohms.

$r_{1}=10 \cdot 0 \mathrm{ohms} . \quad r_{2}=90 \cdot 0 \mathrm{ohms}$.

$\frac{\mathrm{L}}{\mathrm{C}}=100^{2}-90^{2}=1.90 \times 10^{3}$.

$\therefore \mathrm{L}_{i}=0.760$ millihenry.

Victoria College, Stellenbosch, S.A.

VI. On the Radioactivity of the Rocks of the Kolar GoldFields. By Herbert Edmeston Watson, D.Sc. (Lond.), and Gostabehari PaL, M.Sc. (Calcutta)*

THE Kolar Gold Fields are situated on the Mysore 1 plateau in lat. $13^{\circ} \mathrm{N}$, and 50 miles east of Bangalore. The present workings extend along a line about 5 miles long running north and south, and several of them are carried down for 4000 feet, the greatest vertical depth so far reached being about 3600 feet. The "country rock" in which the quartz lies consists of schists, and is apparently of a very uniform nature throughout the workings. Cunsequently it was thought that it might be interesting to carry out some estimations of radium with a view to determining whether its distribution in this homogeneous rock was uniform.

A few estimations of the radium in some of the other rocks from the same locality have also been made for the sake of comparison.

The following is a description of the method used and the results obtained :-

\section{Experimental.}

The method used for the estimation of radium was a modification of Joly's fusion method (Phil. Mag. xxii. 1911, p. 134). It is perhaps not capable of quite general application, but it proved very efficacious for all the rocks dealt with in the present experiments. The principle consisted in the fusion of the rocks with potassium hydroxide under reduced pressure; and the results obtained appear to show that by this means the radium emanation is liberated just as completely as by the higher temperatures necessitated by fusion

* Communicated by the Authors. 
with alkaline carbonates. A thick copper flask $A$, of about 300 c.c. capacity, with a long neck upon which was soldered an outer tube to form a water-jacket, was used to effect the decomposition. 10 grams of the rock, powdered so as to

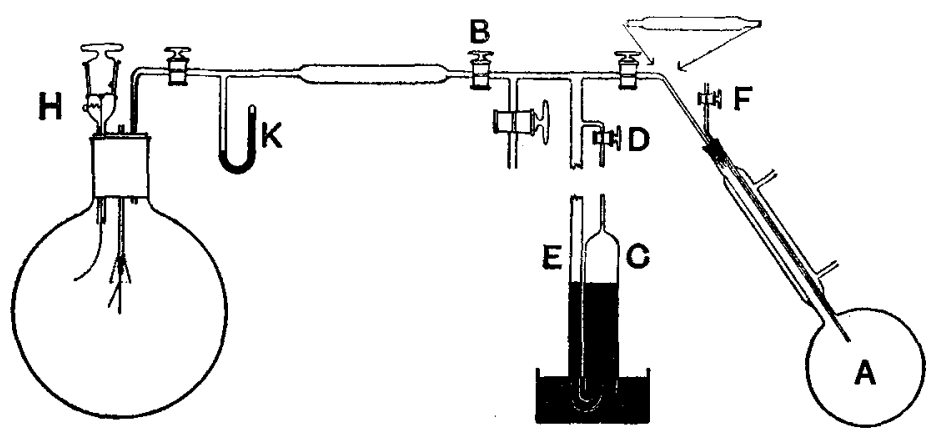

pass through a 120-mesh sieve, were mixed with 2 grams of anhydrous sodium carbonate and introduced into the flask, and 50 grams of stick potassium hydroxide added. The last was not fused to remove water previous to use, as it has been shown that vigorous ebullition assists in the liberation of the emanation. The flask was then connected to the rest. of the apparatus as shown, by a rubber stopper, and the whole evacuated with a Fleuss pump to a pressure of about $1 \mathrm{~cm}$., as shown by the small manometer $K$. The tin $B$ was then closed and the flask and contents heated with a large Teclu burner for 15 mirutes, a very rapid stream of water being passed through the neck. A certain amount of gas was usually liberated, and in the earlier experiments the pressure sometimes rose to such an extent that the cork was blown out of the flask. To avoid this, a safety-valve was devised. The tube E, slightly greater in length than the barometric height, was attached to the apparatus, and bent round under the wider tube $(\mathrm{C}$ about 50 c.c. in capacity, the joint being under mercury. If the pressure rose much above that of the atmosphere, gas escaped into C. The gas liberated was on one occasion pumped off, and found to be almost perfectly pure hydrogen.

After heating, the copper flask was cooled in water and the pressure fell sufficiently to cause $\mathrm{C}$ to fill with mercury when the tap $\mathrm{D}$ was opened. The taps leading to the electroscope were then very cautiously opened and the gas washed out of the flask and drying-tubes which contained calcium chloride, fused potissium hydroxide, and phosphoric 
anhydride, by opening the tap $\mathrm{F}$ connected to a tube leading nearly to the bottom of the flask. The electroscope itself was similar to those used by Joly, but about twice as sensitive. The moving leaf was of aluminium about $30 \times 2 \mathrm{~mm}$, and a small piece of quartz fibre attached to the end and illuminated from the side, made it possible to take readings to the tenth part of a scale-division with ease. The insulation was a quartz tube with a sulphur rod shaded by black paper on the end. Charging was effected by means of a wire movable through an air-tight groundglass joint $H$. A potential of 300 volts from a battery was used, and the wire always replaced in the same position and earthed after charging. The whole was contained in a 500 c.c. glass flask silvered on the inside except for two small holes, and earthed.

The quartz fibre was observed through a small microscopo with a scale in the eyepiece. The constant was determined roughly at first by weighing out 5 milligrams of Joachimsthal pitchblende which was mixed with a little rock and fused up in the usual way. This quantity was found to be much too large, and so 10 milligrams were accurately weighed, well digested with nitric acid, and the solution made up to 100 c.c. 1 c.c. of this was taken and evaporated to dryness in a small glass capsule. After three weeks this was fused up with 25 grams of potassium hydroxide, and the resulting leak determined. Two such determinations were made at intervals of eight months with different portions of pitchblende, and in the second case twice the quantity was taken.

These two experiments gave the quantity of radium which produced a leak of 1 scale-division per hour as $0.310 \times 10^{-12}$ gram and $0.315 \times 10^{-12}$ gram respectively. Another preliminary experiment with a different leaf gave $0.275 \times 10^{-12}$ gram. The pitchblende was found to contain 60.0 per cent. of uranium; and it was assumed that the amount of radium in equilibrium with 1 gram of uranium was $3 \cdot 15 \times 10^{-7}$ gram (Pirret \& Soddy, Phil. Mag. [6] xxi. 1911 , p. 652).

The natural leak was fairly constant. It varied from $5 \cdot 5$ to $6 \cdot 2$ scale-divisions per hour, and was determined at frequent intervals.

The materials used for fusion appeared to be fairly free from radioactive matter. Blank experiments showed that a correction of about 1 scale-division per hour for 50 grams was necessary.

It was found at once that the quantity of radium in the rocks under examination was very minute; and in order to 
be quite sure that this was not due to faults of the method or of the apparatus, a number of experiments were made.

No increase in the leak was observed if the heating was continued for more than 15 minutes. The resulting melt nearly all went into solution on treatment with water, and then hydrochloric acid. To be certain, however, that the emanation had been expelled, these solutions, which were quite clear, were kept for three weeks and then boiled under reduced pressure and the gas introduced into the apparatus, following the original method of Soddy (Roy. Soc. Proc. Ixxvi. 1905, p. 88). The small insoluble residue was also brought into solution by fusion with carbonates, and the solutions added to the others. Only a very slight increase in the natural leak was ever observed, although a control experiment with a solution to which 1 c.c. of the uranium nitrute solution previously mentioned had been added, showed that this method was not at fault, even though the results wero lower than those obtained by the other method.

Although other observers have shown that very little emanation is given up by a mineral on reducing the pressure of the air in the vessel containing it, an experiment was carried out in order to test this, in which only the electroscupe was evacuated. No abnormal result was obtained. The method of sweeping out the gas from the copper flask was also found to remove at least 95 per cent. of the emanation; and as all determinations were carried ont in exactly the same way, no error should arise from this cause.

In all normal cases electroscope readings were taken half hourly, for about 3 hours, starting about $1 \frac{1}{2}$ hours after admission of the gas, and the rates of leak reduced to their maximum value by means of the curve given by Satterly (Phil. Mag. xx. 1910, p. 2).

The decay curve after three to four hours corresponded approximately with that of radium emanation, although an accurate determination was difficult owing to the extremely small quantities of gas.

After a considerable number of determinations lad been made, an important source of error was discovered owing to one specimen of rock giving rise to a leak which was less than the normal leak of the electroscope. This was found to be due to the presence of a large quantity of hydrogen in the evolved gas. As the available data on ionization in hydrogen are very meagre, some experiments were carried out to determine the magnitude of the effect. It was found that the natural leak in hydrogen was 1.0 scale-division an hour, while in air it was 60 . Also in an experiment with urnnium 
nitrate similar to the others, but in which the apparatus was filled with hydrogen instead of air, a leak of 36.5 scaledivisions per hour was observed, while the same weight of the salt produced a leak of 133.5 scale-divisions per hour in air.

Using these data, and assuming that the rate of leak is a linear function of the quantity of hydrogen (a doubtful assumption), it may be calculated that if 100 c.c. of hydrogen are introduced into an electroscope of 500 c.c. capacity, a leak of 15 divisions per hour would be reduced to 12.7 and one of 10 to 8.4 . With a natural leak of 5 it will be seen that the error in the latter case is nearly 100 per cent., and 100 c.c. is not at ali an unusualiy large quantity of hydrogen to be evolved.

As the actual leaks increase in magnitude the relative error decreases, but becomes hy no means negligible.

In consequence of this, all the experiments which had been done were repeated with a tube of red-hot copper oxide inserted between the heating flask and the first tap. The effects of this were very satisfactory, as the pressure never rose above nalf an atmosphere during the fusion; and after cooling the flask, it was rarely $30 \mathrm{~mm}$. more than the initial pressure. Even if this were due entirely to hydrogen which was not absorbed in its subsequent passage over the copper oxide, the amount (10 c.c.) would be insufficient to influence the results.

It was found best to keep the electroscope continuously charged ; consequently at the end of each day's readings it was evacuated to a pressure of about $10 \mathrm{~mm}$; and if the rock which had been examined had contained more than the usual excessively small quantity of radium, air was again admitted, and pumped out. At this pressure the leak was only 0.3 division per hour, and consequently the fibre would remain on the scale for a long period. Immediately after the electroscope had been filled with fresh emanation, it was charged to a higher potential, so that the pointer reached a spot about 15 divisions off the scale, and no readings were taken for at least an hour (except in the case of large leaks). The reason for this was that the leaf fell very rapidly at first if charged up directly from zero potential owing to some " soaking in" effect of uncertain duration.

The sensitiveness of the electroscope remained practically constant over the whole scale, as might be expected from the potential to which it was charged ( -300 volts); but the final values were as far as possible deduced from readings over the same part of the scale owing to a slight variation in parts which was evidently due to rigidity of the leaf. 


\section{The Results.}

Mr. H. M. A. Cooke of Kolar very kindly supplied us with large specimens of " country rock" selected at varying depths from each of the chief mines. These were firs', roughly crushed in order to obtain fair samples.

The following table shows the amount of radium per gram of rock in units of $10^{-14}$ gram.

The depths from which the samples were taken are only approximate, and are measured along the incline of the shaft. The actual vertical depths are usually considerably less, for instance, 4000 feet on the incline in the Mysore mine is only 2664 feet below the surface. As, however, the shafts follow the direction of the strata, a comparison made in this way is probably preferable to one made at equal vertical depths.

The names of the mines are given as they occur geographically, Balaghat being the most northerly.

TABLe I.

\begin{tabular}{|c|c|c|c|c|}
\hline \multirow{2}{*}{ Name of Mine. } & \multicolumn{4}{|c|}{ Depth in feet. } \\
\hline & 1000 . & 2000 . & 3000 . & 4000. \\
\hline 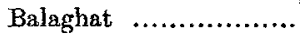 & 21 & 14 & 21 & $\cdots$ \\
\hline Nundidroog ................ & 17 & $\ldots$ & 14 & $\cdots$ \\
\hline Ooregum $\ldots \ldots \ldots \ldots \ldots . . . .$. & 18 & 17 & $\ldots$ & 21 \\
\hline Champion................... & $\ldots$ & 24 & 18 & 14 \\
\hline 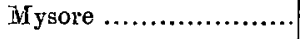 & 34 & 21 & 23 & 96 \\
\hline
\end{tabular}

It will at once be seen from the above that there is no obvious relation between the radium content and the position of the rock; and in fact, with two exceptions, the numbers are almost the same within the limit of experimental error. It thus appears that the distribution of radium is uniform.

With regard to the high value for the deepest sample from: the Mysore mine, a second experiment showed the figure to be correct; but il was found on subsequent examination that the rock was of quite a different character to the others, being probably a later formation.

A few other samples of rock, the geological history of which was known to some extent, were kindly presented to us by Dr. Smeeth of the Mysore Geological Department, and the radium content was determined. As these rocks were of

Phil. Mag. S.6. Vol. 28. No. 163. July 1914. E 
a different character to those previously dealt with, the melt was in all cases treated with water and hydrochloric acid, and any residue weighed to see if the decomposition had been sufficiently complete.

TABLe II.

\begin{tabular}{|c|c|}
\hline Rock. & Radium Content $10^{-12} \mathrm{grm}$. \\
\hline 1. Ooregum 2000 aitered $\ldots \ldots \ldots \ldots \ldots \ldots \ldots \ldots \ldots \ldots \ldots \ldots \ldots \ldots$ & $0 \cdot 18$ \\
\hline 2. Schist subsequently altered $\ldots \ldots \ldots \ldots \ldots \ldots \ldots \ldots$ & 0.82 \\
\hline 3. Very auriferous quartz $\ldots \ldots \ldots \ldots \ldots \ldots \ldots \ldots \ldots \ldots \ldots \ldots$ & $1 \cdot 28$ \\
\hline 4. Quartz same age as 3 , much less gold $\ldots \ldots \ldots$ & $1 \cdot 3 \pm$ \\
\hline 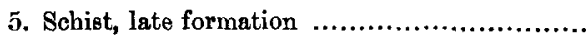 & $1 \cdot 44$ \\
\hline 6. Quartz containing tourmaline, same age as $5 .$. & $6 \cdot 90$ \\
\hline
\end{tabular}

The first of these samples was picked out from the piece of rock used for the detcrmination given in Table I. It differed considerably from the rest of the rock, and it was thought that the radium content of the two portions might not be the same. As may be seen, however, the two were almost identical. Samples 2, 3, and 4 were of approximately the same age, and related geologically to the deepest sample from the Mysore mine. A comparison of 3 and 4 seems to show that the quantity of radium does not vary greatly with the gold content. The comparatively large amount of radium in sample 6 did not appear to be due to the tourmaline, as a determination made on a small quantity of the latter gave no abnormally high result.

One sample of water from a large spring at the bottom of the Balaghat mine was also examined, both by boiling some of the water and by fusing the residue from over 2 litres after it had stood for three weeks. Any radium was present in such small quantities that it was practically undetectable.

It is interesting to note that these rocks, which are probably some of the oldest known, contain so little radium. In fact, the quantity appears to be equal to the smallest quantity hitherto estimated in any rock. Also, as may be soen from Table II., there appears to be some slight tendency of the radium content of the rocks of this locality to increase as their age diminishes; but the number of experiments is not sufficient to show that this is definitely the case. Dr. Smeeth has promised to secure a number of additional 
specimens, and any results obtained will be given in due course.

In connexion with the small radiam content of these rocks, it is worthy of note that the temperature gradient in the Kolar mines is quite abnormally small; and it is hoped that a communication on this subject may be made at some future date.

\section{Summary.}

1. The radium content of a number of similar schists from different parts of the Kolar Gold Field has been examined by means of a new method which involves the fusion of the rock with potassinm hydroxide under reduced pressure.

2. The quantity of radium in these schists appeared to be approximately constant, and has a mean value of $0.19 \times 10^{-12}$ gram per gram of rock.

3. A few other specimens of different rocks of later date were found to contain larger quantities of radium varying from 0.82 to $6.90 \times 10^{-12}$ gram per gram.

Indian Institute of Science, Bangalore.

\section{The Collapse of Short Tubes by External Pressure.} By Gilbert Cook, M.Sc., Assoc.M.Inst.C.E.*

[Plate I.]

$\checkmark$ THE subject of the resistance of tubes to collapse by external pressure is one in which, considering its important practical applications, comparatively little experimental work has been done; moreover, the greater part of this has referred to tubes whose length is very great compared with the diameter, and the most important researches have included little, if any, reference to the strength of short tubes†.

The experimental work of Carman $\ddagger$ and Stewart $\S$ has shown that the relation indicated by theory, namely, that the collapsing pressure is proportional to the cube of the ratio of thickness to diameter, is substantially true for long tubes,

* Communicated by Prof. J. E. Petavel, F.R.S.

$+\mathbf{A}$ full discussion, and bibliography, of the present state of knowledge in regard to tube collapse by external pressure, is given by the author in a report to the British Association Committee on Complex Stress Distribution. See British Association Report, Birmingham, 1913.

$\ddagger$ University of Illinois Bulletin, vol. iii. No. 17, June 1906.

Transactions of the American Society of Mechanical Engineers, 1905-1906, vol. xxvii. pp. $730-822$. 